\title{
Pebble Bed Reactor Fuel Cycle Optimization using Particle Swarm Algorithm
}

\author{
Barak Tavron ${ }^{1}$, Eugene Shwageraus ${ }^{2}$ \\ (1) Planning, Development and Technology Division, Israel Electric Corporation Ltd., P.O. Box 10, Haifa \\ 31000, Israel \\ (2) Department of Engineering, University of Cambridge, Trumpington Street, Cambridge CB2 1PZ, UK
}

\begin{abstract}
Pebble bed reactors (PBR) features, such as robust thermo-mechanical fuel design and on-line continuous fueling, facilitate wide range of fuel cycle alternatives. A range off fuel pebble types, containing different amounts of fertile or fissile fuel material, may be loaded into the reactor core. Several fuel loading zones may be used since radial mixing of the pebbles was shown to be limited. This radial separation suggests the possibility to implement the "seedblanket" concept for the utilization of fertile fuels such as Thorium, and for enhancing reactor fuel utilization. In this study, the Particle-Swarm meta-heuristic evolutionary optimization method (PSO) has been used to find optimal fuel cycle design which yields the highest natural uranium utilization. The PSO method is known for solving efficiently complex problems with non-linear objective function, continuous or discrete parameters and complex constrains. The VSOP system of codes has been used for PBR fuel utilization calculations and MATLAB script has been used to implement the PSO algorithm. Optimization of PBR natural uranium utilization (NUU) has been carried out for 3000MWth High Temperature Reactor design (HTR) operating on the Once Trough Then Out (OTTO) fuel management scheme, and for 400MWth Pebble Bed Modular Reactor (PBMR) operating on the Multi-Pass (MEDUL) fuel management scheme. Results showed only a modest improvement in the NUU $(<5 \%)$ over reference designs. Investigation of Thorium fuel cases showed that the use of HEU in combination with thorium results in the most favorable reactor performance in terms of uranium utilization. The results revealed that neutronics characteristics of the PBR technology are only marginally affected by the fuel management choices.
\end{abstract}

\section{INTRODUCTION}

Pebble Bed Reactors (PBRs) are variant of the HTGR technology, where the fuel is in the form of pebble instead of the more common tall cylindrical fuel elements in prismatic blocks or fuel assemblies. PBRs are graphite moderated and helium cooled, hence may operate at high temperatures $\left(\sim 950{ }^{\circ} \mathrm{C}\right)$ which leads to high thermal efficiency. A large number (500-20000) of Tristructural-isotropic (TRISO) fuel particles are embedded in a $6 \mathrm{~cm}$ diameter graphite fuel pebble. The TRISO coated fuel particles which evolved over decades of research include a heavy-metal fuel kernel coated by 4 layers of 3 materials for fission product retention and isolation. PBRs are also characterized by inherent safety features due to the melt resistant graphite core structure and to the excellent fission-product retention capabilities of the TRISO 
fuel particles. These promising features promoted the HTGR and PBR technologies in leading research and development programs such as Generation IV International Forum (GIF) (1) and Next Generation Nuclear Plant (NGNP) (2).

The spherical shape of fuel pebbles allows for on-line continuous refueling, where fuel pebbles are loaded to the top of the core and unloaded from the bottom. Typical cylindrical core designs contain from $\sim 200000$ to $\sim 1000000$ fuel pebbles for $150 \mathrm{MWe}$ to $1000 \mathrm{MWe}$ reactor designs. Depending on fuel cycle design and refueling machine capabilities, loading/unloading rate can vary between $\sim 300$ to $\sim 9000$ pebbles/day (3). The continuous fuel management feature low excess reactivity, thus neutron poisons are not required and control rods are only needed for the startup and shutdown of the reactor. This leads to more efficient neutron economy and better safety. The drawback is the need for a complex refueling machine.

The AVR 15MWth research PBR operated from 1967 to 1988 at the Julich Research Center, gaining valuable experience which led to the construction of the THTR300, 300MWe commercial reactor in Schmehausen, West Germany. The THTR300 generated electricity from 1985 to 1989 with Uranium-Thorium fuels. It was closed and decommissioned due to a combination of technical and political problems (4). The HTR10 10MWth research PBR at Tsinghua University in China achieved first criticality in 2003. The HTR10 is part of China's HTGR development program, and a scale-up demonstration plant, the HTR-PM 200 MWe started construction in 2009_(5).

PBR fuel management includes the decisions on loading, discharging, storing, repossessing and disposal of fuel pebbles. The on-line refueling feature of PBR fuel management may be considered as part of the reactor control operations since whenever core reactivity drops, reactive fuel pebbles (fresh or partly burned) are inserted to maintain criticality. In this study, two PBR fuel management schemes where investigated (Figure 1):

(1) MEDUL (MEhrfachDUrchLauf- "multi-pass" in German) fuel management implies discharge and re-introduction of fuel pebbles into the core several times (4-20 times) until reaching their target burnup. The reactor design includes a fuel recirculation system which detects the burnup level of the discharged pebbles (by gamma-ray spectrometry (6)) and controls the reshuffling operations. Pebbles which reach the target burnup level are discharged from the system (to spent fuel storage); otherwise they are reintroduced into the core. Hence, mixtures of fresh and partly burned pebbles are continuously charged into the core reducing the power peaking and lowering the axial power peak location. The MEDUL scheme features improved safety and more efficient neutron economy (reduced leakage).

(2) Once-Through-Then-Out (OTTO) fuel management scheme is where fuel pebbles are discharged for disposal after single pass through the core. The flow rate of the fuel pebbles is designed such that the discharged fuel burnup level will not exceed the permitted level. The OTTO scheme features a simpler design and operation, since it does not require a fuel reshuffling system. However, the OTTO scheme features higher power peaking with higher maximum power level located at the upper core region. Moreover, higher neutron flux at the core upper part may increase the differential control rod worth (reactivity change per unit 
length of insertion depth) at upper core area and reduce differential control rod worth at lower part of the core. For reducing the flux and power levels at the reactor top, several OTTO reactor designs introduce burnable poisons into the fuel.

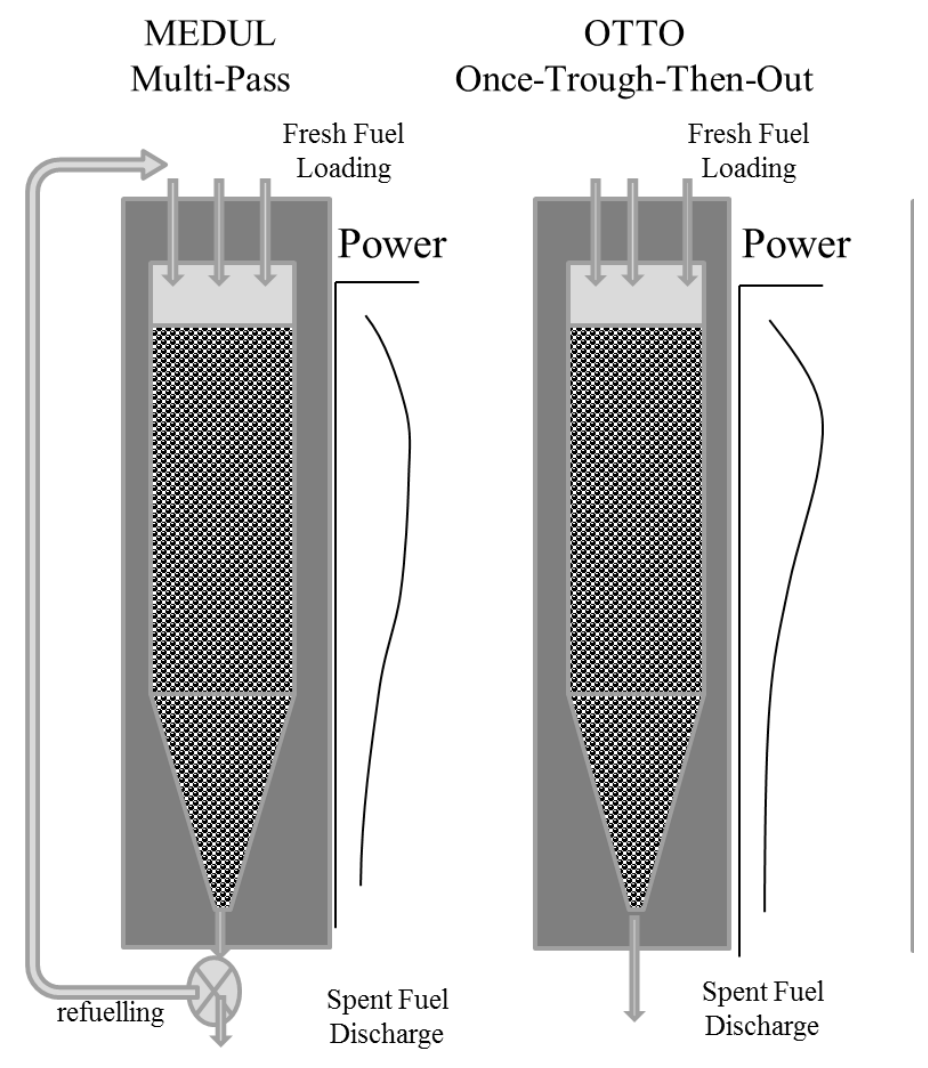

Figure 1: Pebble-Bed reactor fuel management schemes

A number of previous studies (3) (7) (8) (9) (10) investigated different pebble geometric arrangements together with different fissile/fertile material content $(\mathrm{U}, \mathrm{Pu}, \mathrm{Th})$ has been carried out in order to improve the reactor performance. These investigations demonstrate the flexibility of the PBR design.

Experiments and simulation of the pebble movement through the core revealed that the pebble flow is almost "laminar" - fuel pebble moves vertically downwards with negligible cross-flow (pebbles flow in "Channels"). Pebbles flow rate adjacent to the reflector is slightly slower, due to the increased friction; as ratio of core height to diameter increases, pebble flow velocity becomes uniform (slug flow). Hence, when loading several fuel pebble types to different radial zones, separation between fuel types is maintained along the core. The radial separation enables the implementation of the seed-blanket concept (11), when loading seed and blanket fuel pebbles in separate channels.

The thorium based SBU (Seed Blanket Unit) fuel concept was originally proposed by Prof. A. Radkovsky for application to Pressurized Water Reactors (PWR) (11). In PWR cores, the idea is to separate spatially between fissile material (Seed - Enriched Uranium) and fertile material (Blanket - Thorium). This separation is more neutronic efficient since at $\mathrm{BOL}$ it reduces the 
competition for neutron absorption between fissile and fertile nuclides resulting in more efficient breeding. When mixed homogenously, at BOL, uranium limits neutron absorption in thorium.

It has been shown (22) (23) that implementation of the SBU concept in PWR decreases the amount of discharge spent fuel by up to $60 \%$, for a given energy production, compared with standard slightly enriched LWR fuel cycle. The rate of plutonium production in the SBU cycle is only $30 \%$ that of a corresponding rate for standard PWR. The amount of heavy metal, required for cycle reload is significantly lower in SBU designs than in conventional PWR core. On the other hand, due to the high enrichment of the uranium (seed) fuel, the quantities of required Separative Work Unit (SWU) are larger. Consequently, the fuel cycle cost is almost the same for all considered designs. Also, in PWR cores, optimal implementation of the SBU concept requires extended burnup both in the seed and in the blanket, beyond current operating PWR experience.

PBR cores have potential for successful implementation of the SBU concept since the pebble fuel elements can withstand very high burnup. Seed separation from blanket is performed by loading in different pebble channels (12).

Introducing Thorium fuel to PBR started in the first research and demonstration plants, the $A V R$, and THTR, without employing the SBU concept. In these reactors, the Uranium and Thorium fuel were homogeneously mixed as (U-Th)O2. Previous research work has revealed that PBR, with separate Uranium and Thorium fuel pebbles, achieve high conversion ratios and even suggested the possibility for breeding ( (13) (14)).

The current study includes investigations of PBR running OTTO fuel management scheme with 1, 2 and 5 loading zones (or fuel channels). MEDUL fuel management scheme was investigated for modular PBR design featuring narrow core design which allows for only single zone fuel loading. Thorium fuels were investigated along high and low enriched uranium, added as mixed-oxide or in separate fuel pebbles.

Loading different fuel types into several loading zones increases the number of fuel cycle design parameters considerably. The simplest case of loading single UO2 fuel type pebble into single fuelling channel, include only two fuel cycle design parameters, HM mass and enrichment. For 5 fuelling channels, each with different fuel pebble type, with various design possibilities (HM mass, enrichment and fuel materials), 15 design parameters influence the fuel cycle performance. Traditionally, fuel cycle has been designed by experts, based on PBR neutron physics knowledge and some parametric studies. Large number of parameters, lead to complex fuel cycle design task. Here, the use of optimization methods is suggested to simplify this process, and possibly revealing superior fuel cycle designs. The Particle-Swarm meta-heuristic evolutionary optimization method (PSO) has been selected for this study, to find optimal fuel cycle design. The PSO method is known for solving efficiently complex problems with non-linear objective function, continuous or discrete parameters and complex constrains.

Fuel cycle optimization objectives are established to ideally achieve reactor operator utility and/or national goals. Common goals are profits maximization, uranium resource 
conservation, enrichment requirement (SWU) minimization, waste mass and radio-toxicity minimization, maximizing safety margins or proliferation threat minimization. Objective function is formed to meet these goals. For achieving several goals simultaneity, the objective function has to be formed by combining weighted contributions of each individual objective or seeking a family of non-inferior solutions which form Pareto front. In this study, the chosen goal is uranium resource conservation; hence the optimization objective is to maximize natural uranium utilization (NUU). PBR core feature high neutron leakage (large dimensions and graphite moderated) resulting with mediocre neutronics performance which may reduce NUU. Efficient fuel cycle design under reactor operational constrains will be the main contributor to maximizing NUU and probably part of almost all other goals mentioned above.

\section{ANALISYS METHODS}

Optimization of PBR fuel cycle involves the choice of fuel compositions and loading strategies that will maximize reactor performance such as fuel utilization, within reactor safety constrains. The definition of the optimization problem, including the optimization parameters, the objective function and the optimization constrains are described below. The PSO optimization algorithm is then described, followed by brief description of the VSOP code system which is used for PBR fuel cycle simulation i.e. calculating the objective function and the compliance with the safety constraints.

\subsection{DEFINTION OF THE OPTIMIZATION PROBLEM}

Uranium resource conservation is the selected goal for this study; hence the optimization objective is to maximize natural uranium utilization (NUU). Thorium resource conservation is neglected since its abundance in nature is much higher than uranium. The presented optimization procedure may be applied for achieving other goals, by altering the optimization objective function. NUU is defined as the power produced in the reactor per the amount of natural uranium required and is calculated using the following expression:

$N U U=\frac{Q}{\sum_{i} m_{U, i} L R_{i} F F_{i}} ; F F_{i}=\frac{F}{P}=\frac{X_{p, i}-X_{w}}{X_{f}-X_{w}}$

Where:

$m_{U, i}$ - Mass of uranium per pebble in zone $i, \mathrm{~kg}$,

$L R_{i^{-}} \quad$ Pebbles feed rate in zone $i, \# /$ day,

$F F_{i^{-}} \quad$ Enriched Uranium feed factor for pebbles in zone $i$,

F- $\quad$ Mass of natural uranium (feed material), kg,

$P$ - $\quad$ Mass of enriched uranium (product material), $\mathrm{kg}$,

Q - Reactor power, MW,

$X_{p, i}$ - Weight fraction of U235 in the product stream of enrichment process

$X_{f}-$ Weight fraction of $\mathrm{U} 235$ in the feed stream (natural $\mathrm{U}-0.7 \%$ ) 
$X_{w}-\quad$ Weight fraction of U235 in the waste stream (tails, we use $0.2 \%$ )

The NUU units are MWDth/kgNU. NUU is calculated for equilibrium core conditions which assess fuel cycle performance, in which the feed fuel rate and enrichment are constant over time. Core power density and temperature calculations are used to screen-out fuel cycle designs which exceed typical PBR operational constrains. We have adopted constraints of maximum pebble power of $4.5 \mathrm{~kW}$ and maximum fuel temperature of $1150{ }^{\circ} \mathrm{C}$ from ref (15). These constrains are generally set to facilitate temperatures that should not exceed the safety limit of $1600{ }^{\circ} \mathrm{C}$ under the worst accident scenario (DLFOC - Depressurized Loss of Forced Cooling). It has to be noted however, that these constraints would vary and depend upon the specific reactor design under consideration and should be adjusted accordingly.

In NUU objective expression above, the fuel cycle optimization parameters are the mass and enrichment of uranium in pebbles for each loading zone $\left(m_{U, i}, X_{p, i}\right)$. Mass of uranium per pebble can range from 3 to $25 \mathrm{~g}$, and uranium enrichment is constrained by the nonproliferation limit of $20 \%$. For mixed oxide thorium fuel $-(\mathrm{U}-\mathrm{Th}) \mathrm{O} 2$, thorium fraction is an additional optimization parameter. Additional investigations of Th-MOX fuel, allowing for high uranium enrichments of up to $93 \%$, were carried out to better assess thorium breeding potential. The HM loading per pebble parameter dictates the moderation ratio in each loading zone. Optionally, graphite pebbles (commonly called "dummy balls") may be added to further tuning of the zone moderation ratio. Investigations of Thorium introduction as ThO2 within separate pebbles were also carried out. For this case the optimization parameter is fraction of Thorium pebbles in each loading zone. Thorium introduction in separate pebbles is aimed for breeder PBR cycles, where the bred thorium pebbles serves as driver fuel in other reactor/cycles (13). Pebble feed rate is calculated to maintain equilibrium core condition by a dedicated script. Feed factor was calculated from the enrichment process parameters.

The VSOP code system is used to simulate the fuel cycle of the reactor. The VSOP is a system of codes for the simulation of pebble-bed reactors with unique treatment of its special features, such as "double heterogeneity" and on-line continuous fuel loading. Unit-cell spectrum calculations in VSOP are performed by the THERMOS, ZUT and GAM codes for the thermal, the resonance and the epi-thermal energy spectrum regions, respectively. These codes apply various approximations to the transport equation to accommodate special features of pebble-type fuel with coated fuel kernels. Power and neutron flux distributions are then calculated by the 2D diffusion program CITATION. Burnup calculations and fuel shuffling operations are performed by the FEVER code. Thermo-hydraulic and fuel cycle cost calculation are performed by THERMIX and KPD codes respectively. PBR fuel cycle is simulated by repeating steps of neutron spectrum, diffusion, burnup, thermal-hydraulics, fuel management and costs calculations. A VSOP user controls the calculation sequence of the fuel cycle simulation.

The pebble feed rate, with specified fuel parameters, which maintain equilibrium core condition, is calculated by independently developed dedicated MATLAB script. In the equilibrium core, the neutron flux, power and material composition do not change considerably over time. The MATLAB script steps are as follows: 
Step 1: Perform burnup calculation for the core loaded with all fresh fuel until its reactivity drops to zero.

Step 2: Perform fuel management operations (core refueling with small batch fuel loading increments) and continue the core burnup simulating reactor life:

- Continuously load and discharge fuel pebbles from the core in small batches (in OTTO fuel management scheme load only fresh fuel). Iterate on reload cycle length (feed rate) to maintain core criticality.

- Repeat core burnup cycles until equilibrium condition is reached (no change in fuel feed rate to maintain criticality).

Step 3: Check compliance with main constraints; Obtain fuel pebbles feed rate $L R_{i}$ from equilibrium core and calculate Natural $U$ utilization

\subsection{PARTICLE SWARM OPTIMIZATION}

PSO is an evolutionary optimization algorithm that is inspired by the social behavior of swarms such as a flock of migrating birds trying to reach an unknown destination (or food). PSO has been found to have superior performance in several benchmarks (16). This stochastic algorithm mimics the behavior of the birds in the flock, which communicate with one another as they fly. In PSO, each solution is a "bird" in the flock and is referred to as "particle". Each bird in the flock looks in a specific direction and also identifies the bird with the best location in the flock. The bird is then speeds to a new location depending on own search progress (own experience) and a global search (flock experience). The process repeats until the flock reaches desired destination (convergence).

The process is initialized with generating a swarm of $\mathrm{N}$ random particles (solutions), which, in our case, we generate using the Latin Hypercube sampling technic (17) to ensure an even sampling from the search space. Each particle $i$ is characterized by a location vector $x_{i}$ and a speed vector $v_{i}$. The location quality of each particle $p_{i}$, is calculated by the objective function, the natural uranium utilization - FU. $G$ represents the global best location of the swarm. Advancing from time step $k$ to $k+1$, each particle updates its location $x_{i}(k+1)$ by the speed vector $v_{i}(k+1)$. The updated speed vector depends on previous speed, previous best location and global best location weighted by the algorithm parameters $w, c_{1}, c_{2}$ and with additional random weighting $\gamma_{1}$ and $\gamma_{2}$. Hence the algorithm formulas are:

$$
\begin{aligned}
& v_{i}(k+1)=w v_{i}(k)+c_{1} \gamma_{1}\left(p_{i}-x_{i}(k)\right)+c_{2} \gamma_{2}\left(G-x_{i}(k)\right) \\
& x_{i}(k+1)=x_{i}(k)+v_{i}(k+1)
\end{aligned}
$$

Some PSO algorithm extensions have been implemented and used: "Maximum velocity", "Queen Particle", "Constriction coefficient" and "Acceleration factor", these extensions are described in ref ${ }^{(8)}$. Based upon tuning experiments for a simplified PBR optimization case, population size of 15 and the learning factors $c_{1}=1$ and $c_{2}=3$ have been selected. 


\section{OTTO fuel cycle optimization}

OTTO fuel management scheme is characterized by a relatively high power peaking (max. power/average power) with maximum power located at the upper core region (Figure 1) since only the fresh fuel is loaded at the top of the core. The non-uniform power distribution shifted towards the top of the core result in higher neutron leakage and increased differential control rod worth at upper axial locations. Introduction of burnable poisons into the fuel pebbles or in dedicated control pebbles is often suggested to flatten the axial power distribution and enhance PBR-OTTO safety and economic performance (18) but was not considered in this study.

The OTTO fuel cycle optimization was carried out for a large PBR design, presented in E. Teuchert comprehensive OTTO fuel cycle investigation work from 1977 (3). PBR characteristics include cylindrical core of $5.89 \mathrm{~m}$ radius and $5.5 \mathrm{~m}$ height, and thermal power rating of $3000 \mathrm{MWth}$. However advanced (modern) TRISO coated particle design has been selected for this study. Fuel and core parameters are presented in Table 1. Figure 2 presents the reactor geometry and compositions layout. Optimizations have been performed for the following fuel configurations: Low Enriched Uranium (LEU) fuel, Thorium-Uranium Oxide (Th-MOX) fuel and mixture of separate Uranium and Thorium fuel pebbles (SEP). Fuel management of 1, 2 and 5 radial fuel loading zones configurations were investigated.

The reactor core is divided into 5 radial "channels", the 4 inner channels are axially divided into 9 fuel batches each and the 5th outer channels is divided into 13 fuel batches. The batch dimensions were selected such that the volume of all fuel batches is the same. The OTTO fuel management scheme is simulated by shifting the fuel batches downwards every time step, and loading fresh fuel batches to the upper core section. The bottom fuel batches are discharged and removed from the system. The higher subdivisions of the outer core channel is intended to simulate the slower fuel pebble flow rate which is due to pebble friction with the reflector. This slower flow rate also means longer residence time for the outer channel fuel pebbles. The neutron flux distribution (spectrum and diffusion) are calculated for the core and reflector region (inside the dashed area of the figure), with reflective boundary conditions at core center and zero incoming current (vacuum) at the outer boundaries. The solid reflector graphite density is $1.7 \mathrm{~g} / \mathrm{cm}^{3}$. For the simulations of the helium flow paths in the upper, bottom and radial reflector areas, reduced graphite density is set according to the flow path dimensions.

Table 1: HTR design parameters

\begin{tabular}{|l|c|}
\hline \multicolumn{2}{|c|}{ Core Design Parameters } \\
\hline Power [MWth] & 3000 \\
\hline Power Density [MW/m3] & 5 \\
\hline Heating of Helium [C] & 250 to 985 \\
\hline Inlet Helium Pressure [atm] & 40 \\
\hline Core Height [cm] & 550 \\
\hline Core Radius [cm] & 589 \\
\hline Pebble packing fraction (fuel volume/core & 0.61 \\
\hline
\end{tabular}




\begin{tabular}{|c|c|c|c|c|}
\hline \multicolumn{5}{|l|}{ volume) } \\
\hline Top Reflector Thickness [cm] & \multicolumn{4}{|c|}{250} \\
\hline Bottom Reflector Thickness [cm] & \multicolumn{4}{|c|}{200} \\
\hline Radial Reflector Thickness [cm] & \multicolumn{4}{|c|}{100} \\
\hline \multicolumn{5}{|c|}{ Fuel pebble design } \\
\hline Pebble Diameter [cm] & \multicolumn{4}{|c|}{6} \\
\hline Inner Fuel matrix Diameter [cm] & \multicolumn{4}{|c|}{5} \\
\hline Graphite Density $\left[\mathrm{g} / \mathrm{cm}^{3}\right]$ & \multicolumn{4}{|c|}{1.7} \\
\hline \multicolumn{5}{|c|}{ Fuel Particle design (TRISO type) } \\
\hline Kernel diameter $[\mu \mathrm{m}]$ & \multicolumn{4}{|c|}{500} \\
\hline Kernel density $\left[\mathrm{g} / \mathrm{cm}^{3}\right]$ & \multicolumn{4}{|c|}{10.5} \\
\hline Coating material (4 layers) & C & C & $\mathrm{SiC}$ & C \\
\hline Coating thickness $[\mu \mathrm{m}]$ & 95 & 40 & 35 & 40 \\
\hline Coating density $\left[\mathrm{g} / \mathrm{cm}^{3}\right]$ & 1.05 & 1.9 & 3.18 & 1.9 \\
\hline
\end{tabular}

The thermal hydraulic calculations included additional reactor structure regions (outside the dashed line in the figure): steel liner surrounding the radial reflector; steel plates at the reactor top and bottom areas; thermal shielding between the reflectors and the top and bottom plates. For simulating the core liner cooling system, gaps with stagnant helium were included ( $\mathrm{He}$ at constant pressure of $40 \mathrm{bar}$ ). Air gap between the liner and the reactor structures was also simulated.

Thermal-hydraulic correlations for main material properties such as thermal conductivity (temperature and burnup dependent) and heat capacity (temperature dependent) from VSOP internal libraries were used. Temperature of $50{ }^{\circ} \mathrm{C}$ was set on the model boundaries. Helium flow rate (set at the coolant inlet - red square in the figure) was adjusted to remove the power generated in the core with given He temperature rise across the core. 


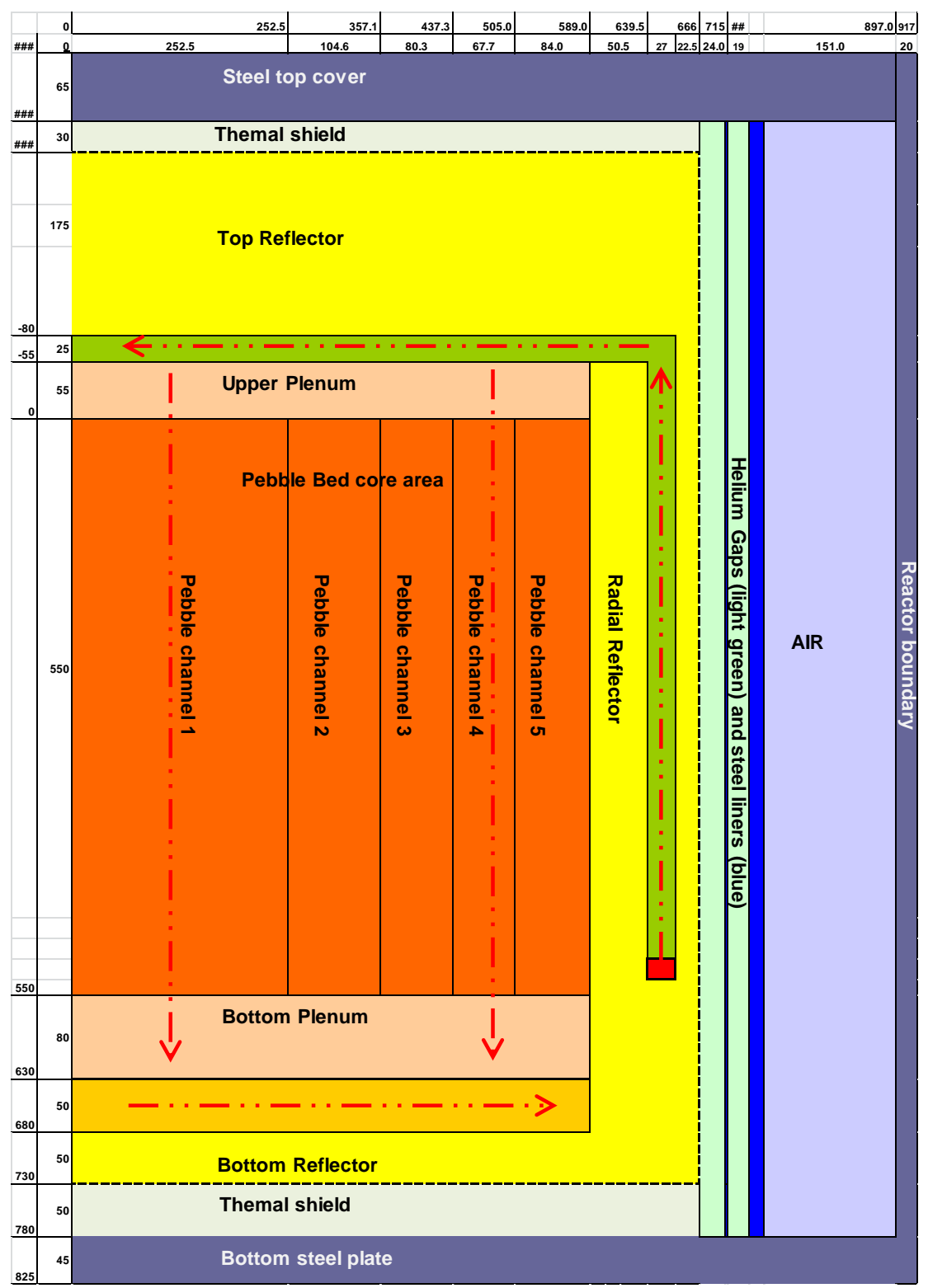

$\underline{\text { Figure 2: HTR reactor layout }}$

Optimization calculations were carried out limiting uranium enrichment to $20 \%$ (due to proliferation concerns). Additional hypothetical case for investigating the potential benefit from driving the Th breeding with highly enriched uranium (HEU up to 93\% enriched, Th-MOX fuel) has been investigated.

Single fuel pebble type is required for fuel management of one loading zone. Two fuel pebble types are required for fuel management scheme with two loading zone; one type into channels 1 to 4 , and one into channel 5 . For fuel management scheme with 5-zone fuel loading, 5 fuel pebble types has been loaded, each into individual channel. Cases notations are composed of the fuel types followed by the number of loading zones. Fuel types are LEU, ThMOX, HEU Th-MOX and SEP; loading zones are $1 Z, 2 Z$ and $5 Z$. 
Single zone loading of LEU fuel case (LEU-1Z) has two optimization parameters, HM enrichment and HM loading per pebble. The number of optimization parameters for multi zone loading is the multiplication of single zone loading by the number of loading zones. Hence for the 2 and 5 loading zone case of LEU fuel type (LEU-2Z and LEU-5Z), the number of optimization parameters will be 4 and 10 respectively. Single zone loading of the Th-MOX fuel case (Th-MOX-1Z) has 3 optimization parameters, the HM enrichment, the HM loading per pebble and the thorium fraction in the MOX. Hence for the 2 and 5 loading zone cases of ThMOX fuel type (Th-MOX-2Z and Th-MOX-5Z); the number of optimization parameters will be 6 and 15 respectively.

The single zone SEP case (SEP-1Z) include 5 optimization parameters: HM enrichment of the Seed pebble, HM loading of the Seed pebble (Uranium), HM loading of the Breed pebble (Thorium), fraction of Seed pebbles in the loading batch and fraction of Breed pebbles in the loading batch. For the SEP cases, allowance has been made to include graphite pebbles in the loading batch for better control of the moderation ratio. The graphite pebble fraction of the loading batch was taken to be complementary to $100 \%$ of the Seed and Breed batch fractions. For simplicity, we retained single Seed and Breed pebble design in 2 and 5 zone SEP cases. The loading batch in each zone may have different fraction of Seed, Breed and Graphite pebbles (2 parameters for each zone). Hence the number of optimization parameters for 2 and 5 zone loading cases will be 7 ( 3 for the fuel design +4 for the loading fractions in 2 zones) and 13 ( 3 for the fuel design +10 for the loading fractions in 5 zones) respectively. Parameters ranges are described in section 2.1.

Table 2 to 4 present the optimization results obtained for the single zone loading, two-zone loading and 5-zone loading schemes.

Optimal NUU results of the different cases range from 6.071 $\mathrm{MWD}_{\mathrm{th}} / \mathrm{kg} \mathrm{NU}$ (NU- Natural Uranium) for the HEU Th-MOX-2Z case to $5.707 \mathrm{MWD}_{\mathrm{th}} / \mathrm{kg}$ NU for the proliferation constrained Th-MOX-1Z case, which presents a maximum difference of $6 \%$ between the cases. This minor difference present low sensitivity to the fuel management parameters and may be attributed to the high neutron efficiency of the PBR-OTTO.

The overall optimal natural uranium utilization of 6.033 and $6.071 \mathrm{MWDth} / \mathrm{kg} \mathrm{NU}$, was found for the thorium mixed oxide fuel with high enriched uranium (for single and two loading zones respectively). The HEU Th-MOX NUU optimal results are only about $4 \%$ higher than those of the LEU cases and about 5.5\% higher than those of the Th-MOX cases with LEU. These optimal results were obtained for the Th-MOX fuel loading with 90\% Thorium content, uranium enrichment of $\sim 80 \%$ and $\mathrm{HM}$ loading of $\sim 15 \mathrm{~g} /$ pebble. Since the HM content in the fuel is high, the moderation ratio is low ( $\sim 260)$ and the core may be under moderated. Accidental moderation insertion (such as "water ingress" accident) has to be investigated to confirm negative moderation reactivity coefficients. Fuel residence time is the highest ( 1500 days) since longer time is needed for the U233 to accumulate and make notable contribution to the total energy produced by the fuel. The high enrichment of the HEU Th-MOX cases results in the lowest SWU utilization value of $\sim 4.65 \mathrm{MWDth} / \mathrm{kg}$-SWU. 
When applying the non-proliferation constraint of $20 \%$ to uranium enrichment, thorium introduction does not offer any advantage in NUU. The low enriched uranium fuel cases have slightly better performance than the proliferation constrained thorium based fuel cases. The optimization of these thorium based fuel cases has resulted in the optimal NUU at the constrained limit of $20 \%$ uranium enrichment; supporting the assumption that thorium based fuels require $\mathrm{HEU}$ for better performance. The optimal proliferation constrained Th-MOX case requires HM loading of $\sim 7.5 \mathrm{~g} /$ pebble, which corresponds to moderation ratio of $\sim 495$.

The SEP cases have similar performance as the Th-MOX cases. The neutron spectrum of the mixture of seed and breed pebbles resembles the mixed oxide neutron spectrum because of the large neutron mean free path in the core compared to the fuel pebble size. However, it can be noticed that SEP cases with multi zone loading (SEP-2Z and SEP-5Z) present more noticeable improvement in NUU than the Th-MOX cases. Separate seed, breed and graphite pebbles of the SEP cases offer higher flexibility in fuel management options. SEP cases have higher power peaking and power per pebble values, because of the non-uniform distribution of power production between the seed and breed pebbles. Power peaking factors for the SEP cases range between 4.5 and 5, while for LEU and Th-MOX cases, the range is 3.1-3.7. Maximum power ( $\mathrm{kW} /$ Pebble) for the SEP cases ranges between 4.2-4.65, while for LEU and Th-MOX cases the range is 3.0-3.4.

LEU cases are the most conventional choice of fuel in future designs (PBMR400, HTR-PM) due to the sound performance and proliferation resistance features. UO2 loading of $\sim 6.8 \mathrm{~g} /$ pebble, enriched to $\sim 9 \%$ was found to be the optimal with respect to NUU. LEU cases also exhibit the best SWU utilization performance of $5.4 \mathrm{MWDth} / \mathrm{kg}$-SWU (due to low enrichment).

This reactor design with a secondary steam cycle requires investigating the consequences of "water ingress" accident. In this accident, neutron moderating material is inserted which may result in reactivity rise, even in cores with high moderation ratios such as the Th-MOX, LEU and SEP cases (moderation ratios $>460$ ) (19).

The multi zone loading fuel management schemes ( $2 Z$ and $5 Z$ ) optimization did not result in any significant improvement in the NUU performance of the PBR-OTTO. This is probably due to efficient PBR core design, featuring online refueling with low excess reactivity, and the minimal use of control rods and burnable poisons.

Our hypotheses that multi zone fuel loading will produce more efficient NUU were not realized. Multi-zone loading which present the SBU concept, is found to be not worthy for improving NUU. We also concluded that the option for mixing graphite pebbles in the SEP cases results in more flexible control of the moderation ratio in the loaded fuel. The optimized SEP-5Z case results (Table 4) in no graphite pebbles in the outer loading zone (adjacent to the side reflector), while the inner fuel loading zone has up to $20 \%$ graphite pebbles. It can be explained by the fact that the outer loading zone already benefits from reflected thermal neutrons from the radial reflector and thus requires fewer moderating pebbles in the outer channel. 
Table 2: HTR OTTO Optimization Results for single loading zone core

\begin{tabular}{|c|c|c|c|c|c|c|c|}
\hline & Case & LEU-1Z & Th-MOX-1Z & $\begin{array}{c}\text { HEU } \\
\text { Th-MOX-1Z }\end{array}$ & \multicolumn{3}{|c|}{ SEP-1Z } \\
\hline \multirow{7}{*}{ 蒙 } & HM Loading (g/pebble) & 6.79 & 7.56 & 15.47 & \multicolumn{3}{|c|}{ Seed: 7.82; Breed: 21.5; Gra.:0 } \\
\hline & \multirow{2}{*}{ Pebble Fraction (\%) } & & & & $S$ & $B$ & G \\
\hline & & & & & 61 & 27 & 12 \\
\hline & HM Enrichment & 0.089 & 0.1 & 0.08 & \multicolumn{3}{|c|}{0.12} \\
\hline & U Enrichment & 0.089 & 0.2 & 0.823 & \multicolumn{3}{|c|}{0.2} \\
\hline & Ave. Th fraction & & $50 \%$ & $90 \%$ & \multicolumn{3}{|c|}{$55 \%$} \\
\hline & Ave Moderation Ratio & 554 & 491 & 234 & \multicolumn{3}{|c|}{442} \\
\hline & $\begin{array}{l}\text { Fuel residence time } \\
\text { (days) }\end{array}$ & 720 & 916 & 1638 & \multicolumn{3}{|c|}{1140} \\
\hline & Load rate (Pebble/day) & 8436 & 6638 & 3710 & \multicolumn{3}{|c|}{5331} \\
\hline & Power Peak Max/Ave & 3.59 & 3.39 & 3.13 & \multicolumn{3}{|c|}{4.61} \\
\hline & $\begin{array}{l}\text { Max. Power (KW/ } \\
\text { pebble) }\end{array}$ & 3.31 & 3.13 & 2.95 & \multicolumn{3}{|c|}{4.26} \\
\hline 旁 & $\begin{array}{c}\text { Max. Fuel Temperature } \\
{ }^{\circ} \mathrm{C}\end{array}$ & 1061 & 1060 & 1070 & \multicolumn{3}{|c|}{1065} \\
\hline & $\begin{array}{l}\text { Discharge Burnup } \\
\text { (MWD/kg) }\end{array}$ & 109 & 125 & 108 & \multicolumn{3}{|c|}{112} \\
\hline & $\begin{array}{l}\text { Fuel Utilization } \\
\left(\mathrm{MWD}_{\mathrm{th}} / \mathrm{kg} \mathrm{NU}\right)\end{array}$ & 5.803 & 5.707 & 6.033 & \multicolumn{3}{|c|}{5.739} \\
\hline & $\begin{array}{l}\text { SWU Utilization } \\
\left(\mathrm{MWD}_{\mathrm{th}} / \mathrm{kg} \text {-SWU) }\right.\end{array}$ & 5.415 & 4.854 & 4.665 & \multicolumn{3}{|c|}{4.865} \\
\hline
\end{tabular}


Table 3: HTR OTTO Optimization Results for 2-loading zones core

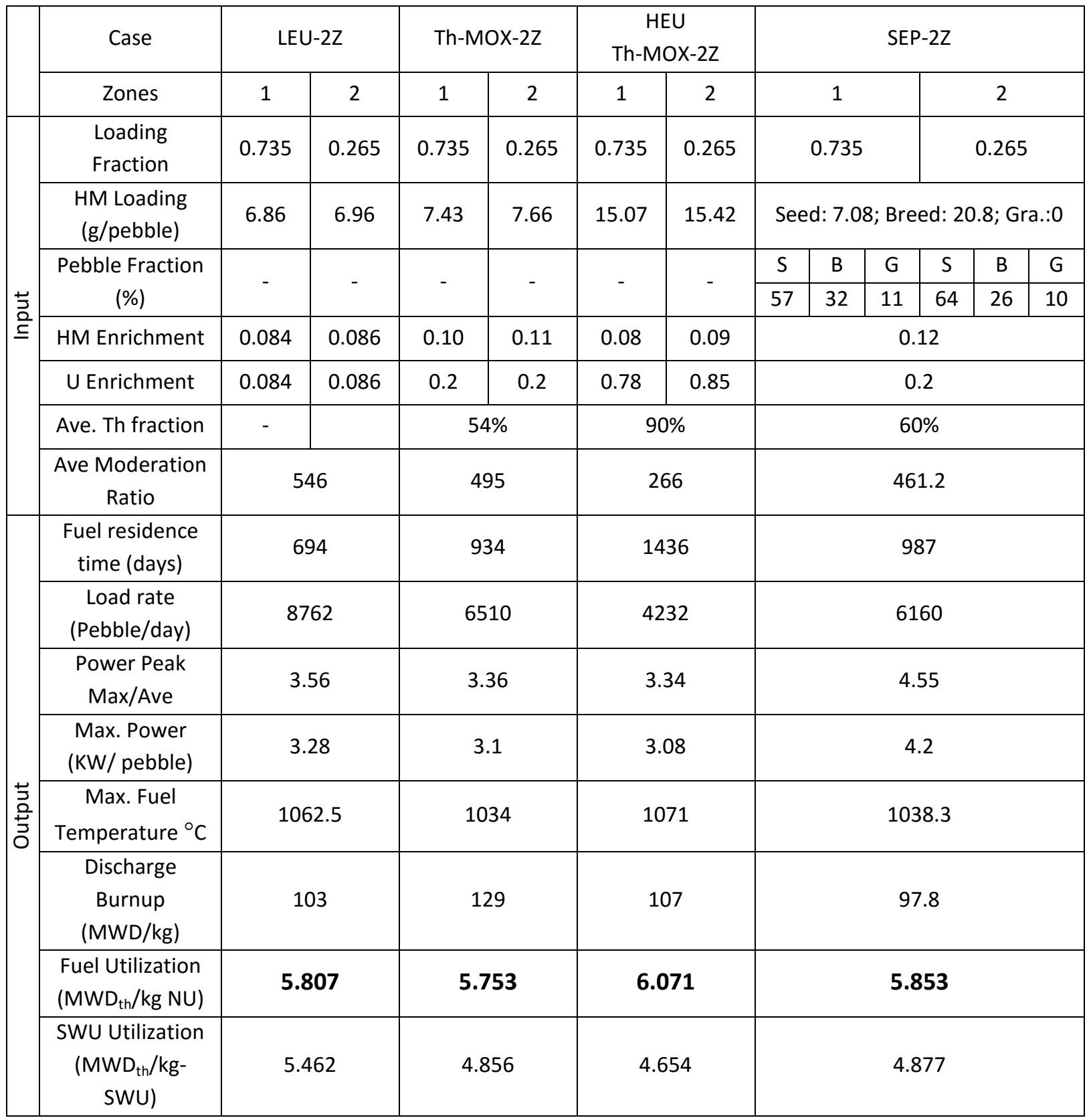


Table 4: HTR OTTO Optimization Results for 5-loading zones core

\begin{tabular}{|c|c|c|c|c|c|c|c|c|c|c|c|c|c|c|c|c|}
\hline & \multirow{2}{*}{$\begin{array}{l}\text { Case } \\
\text { zones }\end{array}$} & \multicolumn{5}{|c|}{ LEU-5Z } & \multicolumn{5}{|c|}{ Th-MOX-5Z } & \multicolumn{5}{|c|}{ SEP-5Z } \\
\hline & & 1 & 2 & 3 & 4 & 5 & 1 & 2 & 3 & 4 & 5 & 1 & 2 & 3 & 4 & 5 \\
\hline \multirow{7}{*}{ 를 } & $\begin{array}{l}\text { Loading } \\
\text { Fraction }\end{array}$ & 0.184 & 0.184 & 0.184 & 0.184 & 0.184 & 0.265 & 0.184 & 0.184 & 0.184 & 0.265 & 0.184 & 0.184 & 0.184 & 0.184 & 0.265 \\
\hline & $\begin{array}{l}\text { HM Loading } \\
\text { (g/pebble) }\end{array}$ & 6.54 & 6.46 & 6.47 & 6.51 & 7.54 & 7.49 & 7.50 & 7.49 & 7.48 & 7.51 & \multicolumn{5}{|c|}{ Seed: 8.90 ;Breed: 15.2415} \\
\hline & $\begin{array}{c}\text { Pebble } \\
\text { Fraction (\%) }\end{array}$ & & & & & & \multicolumn{5}{|c|}{ - } & $\begin{array}{c}\text { S:51 } \\
\text { B:42 } \\
G: 7\end{array}$ & $\begin{array}{l}50 \\
37 \\
13\end{array}$ & $\begin{array}{l}51 \\
35 \\
14\end{array}$ & $\begin{array}{l}51 \\
29 \\
20\end{array}$ & $\begin{array}{c}59 \\
41 \\
0\end{array}$ \\
\hline & $\begin{array}{c}\mathrm{HM} \\
\text { Enrichment }\end{array}$ & 0.089 & 0.098 & 0.097 & 0.075 & 0.078 & 0.1 & 0.1 & 0.1 & 0.1 & 0.1 & & & & & \\
\hline & U Enrichment & 0.089 & 0.098 & 0.097 & 0.075 & 0.078 & 0.2 & 0.2 & 0.2 & 0.2 & 0.2 & & & 0.2 & & \\
\hline & $\begin{array}{l}\text { Ave. Th } \\
\text { fraction }\end{array}$ & \multicolumn{5}{|c|}{-} & \multicolumn{5}{|c|}{0.5} & & & & & \\
\hline & $\begin{array}{c}\text { Ave } \\
\text { Moderation } \\
\text { Ratio }\end{array}$ & \multicolumn{5}{|c|}{564.66} & \multicolumn{5}{|c|}{495} & \multicolumn{5}{|c|}{464.17} \\
\hline \multirow{8}{*}{ 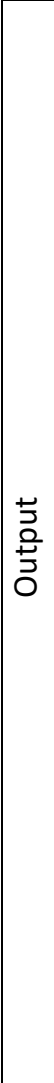 } & $\begin{array}{c}\text { Fuel residence } \\
\text { time (days) }\end{array}$ & \multicolumn{5}{|c|}{701.40} & \multicolumn{5}{|c|}{936} & \multicolumn{5}{|c|}{1032} \\
\hline & \begin{tabular}{|c|} 
Load rate \\
(Pebble/day)
\end{tabular} & \multicolumn{5}{|c|}{8697.21} & \multicolumn{5}{|c|}{6494} & \multicolumn{5}{|c|}{5891} \\
\hline & $\begin{array}{c}\text { Power Peak } \\
\text { Max/Ave }\end{array}$ & \multicolumn{5}{|c|}{3.82} & \multicolumn{5}{|c|}{3.48} & \multicolumn{5}{|c|}{5.04} \\
\hline & $\begin{array}{l}\text { Max. Power } \\
\text { (KW/ pebble) }\end{array}$ & \multicolumn{5}{|c|}{3.53} & \multicolumn{5}{|c|}{3.21} & \multicolumn{5}{|c|}{4.65} \\
\hline & $\begin{array}{c}\text { Max. Fuel } \\
\text { Temperature } \\
{ }^{\circ} \mathrm{C}\end{array}$ & \multicolumn{5}{|c|}{1093} & \multicolumn{5}{|c|}{1061} & \multicolumn{5}{|c|}{1029} \\
\hline & $\begin{array}{c}\text { Discharge } \\
\text { Burnup } \\
\text { (MWD/kg) }\end{array}$ & \multicolumn{5}{|c|}{105} & \multicolumn{5}{|c|}{129} & \multicolumn{5}{|c|}{101} \\
\hline & $\begin{array}{c}\text { Fuel } \\
\text { Utilization } \\
\left(\mathrm{MWD}_{\mathrm{th}} / \mathrm{kg}\right. \\
\mathrm{NU})\end{array}$ & & & 5.809 & & & & & 5.758 & & & & & 5.86 & & \\
\hline & $\begin{array}{c}\text { SWU } \\
\text { Utilization } \\
\left(\mathrm{MWD}_{\mathrm{th}} / \mathrm{kg}-\right. \\
\text { SWU) }\end{array}$ & & & 5.43 & & & & & 4.854 & & & & & 4.94 & & \\
\hline
\end{tabular}




\section{MEDUL fuel cycle optimization}

The MEDUL fuel management scheme feature reshuffling of the fuel pebbles several times through the reactor core until reaching the target burnup (set by safety constrains or by optimal operation values) and removed for disposal or recycling. The burnup level of each pebble exiting the core is measured (by gamma-ray spectrometry (6)), and the reshuffling control system directs the pebble according to that level. Fuel loaded in the MEDUL fuel management scheme is then composed of a mixture of fresh fuel pebbles and partly burned fuel pebbles. The mixture of fuel pebbles of different burnup level is then present along the entire core leading to almost uniform burnup distribution along the core axis (moderate slope, opposed to the steeper slope of the OTTO scheme).

Moreover, the number of fuel passes through the core significantly affects the axial core flux and power distribution. When the fuel pebbles pass only once through the core (OTTO fuel cycle), only fresh (highly reactive) fuel pebbles are loaded, and power density peaks at the upper core region. When fuel pebbles are recirculated more than once through the core, and mixture of fresh and partly burned fuel is loaded, the axial power distribution becomes more uniform and tends towards a cosine shape, lowering the maximum power. Compared to the OTTO scheme, MEDUL presents more efficient neutron economy, where neutron leakage at the upper core area is reduced. Figure presents the PBMR400 core axial power density while operating in the MEDUL fuel management with 1 to 9 fuel reshuffling cycles. Reduction of the maximum power density from $18.1 \mathrm{~W} / \mathrm{cc}$ for single fuel pass through the core (OTTO fuelling scheme) down to $8.4 \mathrm{~W} / \mathrm{cc}$ for reshuffling the fuel pebbles 9 times through the core is observed. Circulating the fuel pebbles more than 6 times through the core results in small additional improvement of the axial power shape. Reshuffling the fuel pebbles for 6 times through the core results in the maximum power density of $9.4 \mathrm{~W} / \mathrm{cc}$ and maximum power located only about 1 meter above the core mid-plane (the total core height is $11 \mathrm{~m}$ ). This result justifies the 6-passes MEDUL fuel cycle design of the PBMR400, which has been adopted in the current optimization study. The 6-passes MEDUL design also considers the fuel charging rate limitations set by the burnup level measuring device and the reshuffling machine. 


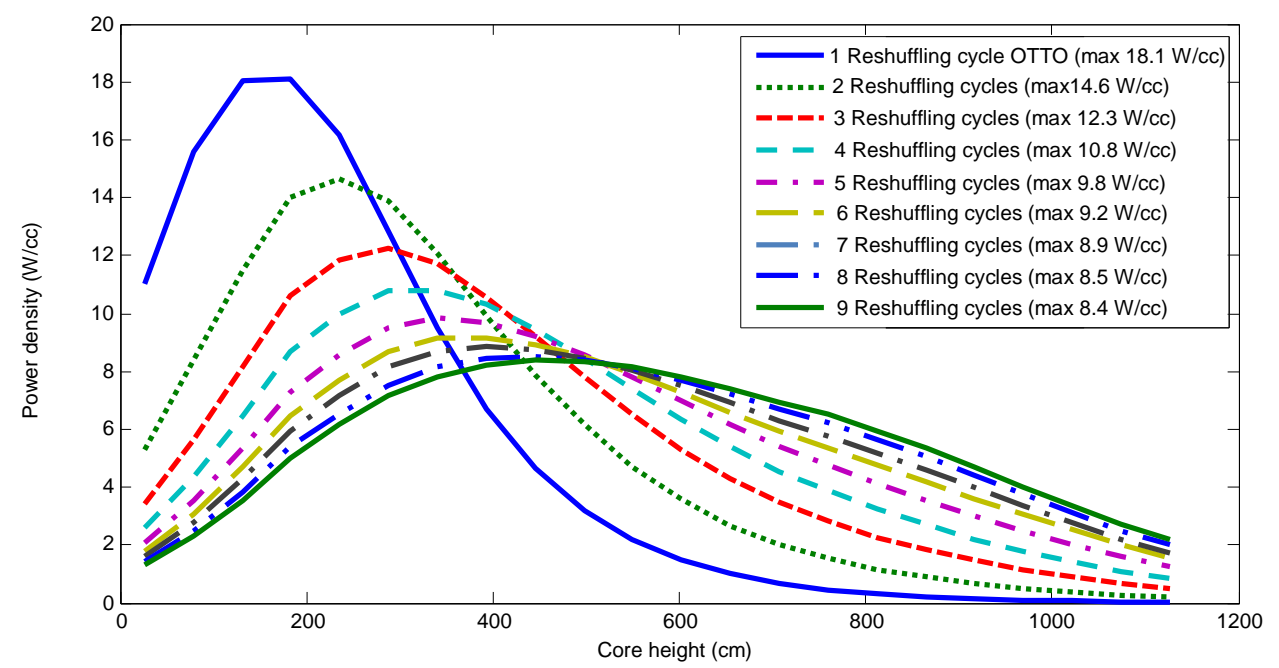

Figure 3: PBMR400 axial power density for 1 to 9 fuel reshuffling cycles

In the current study the MEDUL NUU optimization investigations were carried out for PBMR design of the OECD/NEA/NSC benchmark (20) (21) initiated by the PBMR company from South Africa in 2005. The PBMR400 modular design, proposed by the PBMR company, features an annular core with inner graphite reflector of 1 meter radius and outer radius of 1.85 meter. The core height is 11 meters which contributes to enhanced passive heat removal by natural circulation. A direct cycle, in which the helium coolant from the reactor directly drives the turbine generator, is employed. The helium coolant heats up from $500{ }^{\circ} \mathrm{C}$ to $900{ }^{\circ} \mathrm{C}$ in the reactor core with inlet pressure of 40 bars.

The core geometric model, adopted from Reitsma (22), is presented in Figure . For this study, 5 channels of the reactor core were divided into $24,18,18,18,24$ batches, respectively. As for the HTR core simulation case, the higher batch subdivisions of the fuel channels close to the reflectors is needed to account for the reduced fuel flow rate of the fuel pebbles adjacent to the reflectors (due to friction). The BIRGIT core geometry modelling code, which is part of the VSOP code system (23), has been used for modeling the bottom cones, which simulate the 3 defueling chutes of the PBMR400 design. Main design parameters are presented in Table 5.

The reference design of the PBMR400 MEDUL fuel management scheme has 6-pass recirculating scheme for fuel pebbles containing $9 \mathrm{~g}$ of UO2 enriched to $9.6 \%$, within standard TRISO coated particles. 


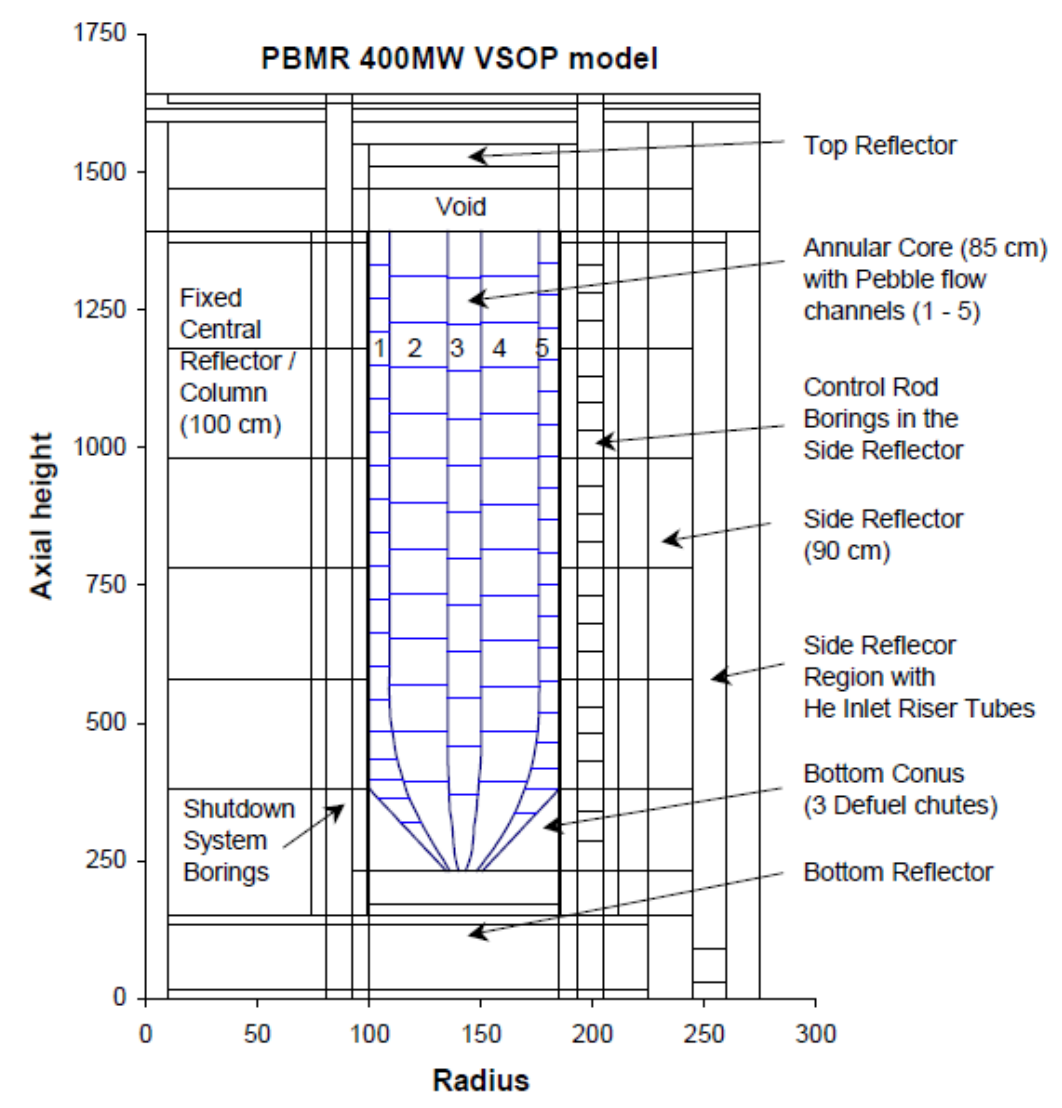

Figure 4: PBMR400 geometry model (from ref (22))

Table 5: PBMR400 design data

\begin{tabular}{|c|c|c|c|c|}
\hline \multicolumn{5}{|c|}{ Core Design Parameters } \\
\hline Power, MWth & \multicolumn{4}{|c|}{400} \\
\hline Power Density, $\mathrm{MW} / \mathrm{m}^{3}$ & \multicolumn{4}{|c|}{5} \\
\hline Helium Inlet/Outlet Temperature, ${ }^{\circ} \mathrm{C}$ & \multicolumn{4}{|c|}{$500 / 900$} \\
\hline Inlet Helium Pressure, atm & \multicolumn{4}{|c|}{40} \\
\hline Core Height, $\mathrm{cm}$ & \multicolumn{4}{|c|}{1100} \\
\hline Core Radius (inner/outer), $\mathrm{cm}$ & \multicolumn{4}{|c|}{$100 / 185$} \\
\hline Pebble packing fraction (fuel vol./core vol.) & \multicolumn{4}{|c|}{0.61} \\
\hline Top Reflector Thickness, cm & \multicolumn{4}{|c|}{150} \\
\hline Bottom Reflector Thickness, cm & \multicolumn{4}{|c|}{400} \\
\hline Radial Reflector Thickness, cm & \multicolumn{4}{|c|}{103} \\
\hline \multicolumn{5}{|l|}{$\begin{array}{ll}\text { Fuel pebble design } \\
\end{array}$} \\
\hline Pebble Diameter, $\mathrm{cm}$ & \multicolumn{4}{|c|}{6} \\
\hline Inner Fuel matrix Diameter, $\mathrm{cm}$ & \multicolumn{4}{|c|}{5} \\
\hline Graphite Density, $\mathrm{g} / \mathrm{cm}^{3}$ & \multicolumn{4}{|c|}{1.78} \\
\hline \multicolumn{5}{|c|}{ Fuel Particle design (TRISO type) } \\
\hline Kernel diameter, $\mu \mathrm{m}$ & \multicolumn{4}{|c|}{500} \\
\hline Kernel density, $\mathrm{g} / \mathrm{cm}^{3}$ & \multicolumn{4}{|c|}{10.4} \\
\hline Coating material (4 layers) & $\mathrm{C}$ & $\mathrm{C}$ & $\mathrm{SiC}$ & $\mathrm{C}$ \\
\hline Coating thickness, $\mu \mathrm{m}$ & 95 & 40 & 35 & 40 \\
\hline Coating density, $\mathrm{g} / \mathrm{cm}^{3}$ & 1.05 & 1.9 & 3.18 & 1.9 \\
\hline
\end{tabular}


Thermo-hydraulic calculations are performed for evaluating compliance with safety constraints. The thermo-hydraulic calculations were performed for a larger reactor model which includes the helium coolant channels, the steel pressure vessel, top and bottom plates and reactor cavity cooling system. Thermo-hydraulic design and materials data were taken from the OECD/NEA/NSC PBMR coupled neutronics/thermal hydraulics transient benchmark (20) definition.

NUU optimizations were performed for the following HM fuel loading: LEU, Th-MOX and HEU Th-MOX. Since the PBMR core is quite narrow in the radial direction (an annulus which is only $85 \mathrm{~cm}$ thick), only single zone loading was considered.

The LEU case includes only 2 optimization parameters, uranium enrichment and heavy metal loading. The Th-MOX and the HEU Th-MOX cases include additional optimization parameter the thorium fraction in the MOX. The optimization parameter ranges for the different cases are described in section2.1. Table 6 presents the MEDUL optimization results.

The highest overall optimal NUU of $5.775 \mathrm{MWDth} / \mathrm{kg}$ NU was found to be for the thorium mixed oxide fuel with highly enriched uranium case. The HEU Th-MOX NUU optimal results are only about $4 \%$ higher than those of the LEU cases and about $5.5 \%$ higher than those of the Th-MOX cases with LEU. Optimal NUU results of the different cases range from 5.775 MWDth/kg NU for the HEU Th-MOX case to $5.379 \mathrm{MWDth} / \mathrm{kg}$ NU for the proliferation constrained Th-MOX case. As in the PBR-OTTO case, performance differences between the cases are relatively minor and can be attributed to the high neutron efficiency of the PBR design and the inherent efficiency of PBR fuel management (online refueling with low excess reactivity).

The optimal NUU results were obtained for the hypothetical HEU Th-MOX fuel with $87 \%$ thorium content, uranium enrichment of 93\% and HM loading of $\sim 17 \mathrm{~g} /$ pebble. The thorium replaces the uranium 238 as the fertile material in the fuel and requires high uranium enrichment for its efficient utilization. Although HEU production at the enrichment facility demands large natural uranium amounts, the overall natural uranium utilization is reduced due to the high thorium content and large energy share from generated U233. SWU utilization results are the lowest compared to the other investigated cases resulting from the high enrichment requirements. The higher HM content in the fuel results in lower moderation ratio $(\sim 200)$ and the core may be under moderated. Moderation insertion has to be investigated to confirm appropriate reactivity response of the core to accidents such as water ingress, even though this kind of accident is very unlikely because of the direct He cycle design of the PBMR400.

The LEU and Th-MOX cases constrained by the non-proliferation limit show similar NUU performance with only about $1.5 \%$ difference between their results. However, SWU utilization is about $5 \%$ better for the LEU case.

Fuel residence times and discharge burnup of the optimal MEDUL cases are about $60 \%$ higher than the optimal OTTO cases since fuel pebbles pass 6 times through the core. The resultant discharge burnup values are higher than $144 \mathrm{MWD} / \mathrm{kg}$. Such high values may require 
additional fuel irradiation experiments to make the fuel licensing case before this scheme can be employed in operational power reactors.

Table 6: PBMR400 MEDUL optimization Results

\begin{tabular}{|c|c|c|c|c|}
\hline & \multicolumn{4}{|c|}{ Optimization Results } \\
\hline & Case & LEU & Th-MOX & HEU Th-MOX \\
\hline \multirow{5}{*}{$\begin{array}{l}\stackrel{+}{\overrightarrow{2}} \\
\stackrel{\text { In }}{2}\end{array}$} & HM Loading (g/pebble) & 10.66 & 10.57 & 17.49 \\
\hline & HM Enrichment & 0.138 & 0.137 & 0.12 \\
\hline & U Enrichment & 0.138 & 0.2 & 0.929 \\
\hline & Ave. Th fraction & - & $29 \%$ & $87 \%$ \\
\hline & Ave Moderation Ratio & 360.1 & 351.6 & 206.4 \\
\hline \multirow{8}{*}{ 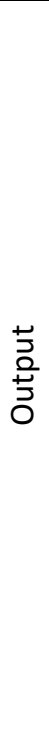 } & $\begin{array}{l}\text { Fuel residence time } \\
\text { (days) }\end{array}$ & 1680 & 1653 & 2641 \\
\hline & Load rate (Pebble/day) & 1572 & 1575 & 999 \\
\hline & Power Peak Max/Ave & 3.29 & 3.14 & 3.3 \\
\hline & $\begin{array}{l}\text { Max. Power (KW/ } \\
\text { pebble) }\end{array}$ & 3.05 & 2.84 & 3.64 \\
\hline & $\begin{array}{l}\text { Max. Fuel Temperature } \\
{ }^{\circ} \mathrm{C}\end{array}$ & 1041 & 1048 & 1093 \\
\hline & $\begin{array}{l}\text { Discharge Burnup } \\
\text { (MWD/kg) }\end{array}$ & 152 & 150 & 144 \\
\hline & $\begin{array}{l}\text { Fuel Utilization } \\
\left(\mathrm{MWD}_{\mathrm{th}} / \mathrm{kg} \mathrm{NU}\right)\end{array}$ & 5.54 & 5.46 & 5.78 \\
\hline & $\begin{array}{l}\text { SWU Utilization } \\
\left(\mathrm{MWD}_{\mathrm{th}} / \mathrm{kg}-\mathrm{SWU}\right)\end{array}$ & 5.41 & 5.12 & 4.88 \\
\hline
\end{tabular}

\section{Summary and conclusions}

A procedure for the optimization of pebble bed reactors fuel management, utilizing PSO algorithm has been developed. This procedure has been used for optimizing the natural uranium utilization of a large $3000 \mathrm{MWth}$ core, operating with an OTTO fuel management scheme and for small modular 400MWth PBMR core operating with MEDUL fuel management scheme. The optimizations have been carried out under typical thermo hydraulic PBR safety constrains. Fuel management performance has been evaluated by the VSOP code system for equilibrium cycle conditions. The presented optimization procedure may be simply altered for achieving other optimization objectives such as minimizing fuel cycle costs, increasing proliferation resistance (minimizing Pu production) or maximizing safety margins (minimizing operating temperatures). Multi objective function which combines weighted contributions from several desired objectives may be implemented as well, thus achieving the needed balance between safety and economics goals. For example, water ingress reactivity effects 
must be limited, which relates to the HM loading and the specific design (direct Helium cycle design have low water ingress probability, versus indirect design with secondary steam cycle).

Multi zone fuel loading schemes, of two and five zones, has been investigated for the large PBR-OTTO. MEDUL fuel cycle has been investigated for the PBMR400 core with the reference design of six fuel recirculation passes loading scheme. Thorium introduction in the form of mixed Th-U oxide (Th-MOX) fuel and in separate ThO2 fuel pebbles mixed with UO2 breeder fuel pebbles (SEP) has been investigated. For the Th-MOX fuel, cases with uranium enrichment constrained to the non-proliferation level of $20 \%$ and a hypothetical HEU case were investigated.

Results indicate that NUU of the PBR technology has relatively low sensitivity to the fuel management parameters and the optimization studies revealed only a modest improvement in the NUU (<5\%). This result may be attributed to the PBR efficient neutron economy due to online refueling with minimal excess reactivity and minimal use of neutron poisons and control rods.

Investigation of Thorium fuel cycles revealed that HEU must be used in combination with Thorium in order to improve NUU. Still, the use of thorium even with HEU improved NUU by only about $4.5 \%$ for the PBR-OTTO and for the PBMR400-MEDUL. The introduction of thorium along with LEU had even smaller impact on the NUU for both the PBR-OTTO and PBMR400 designs leading to a reduction of about $1 \%$ in NUU.

The optimized Thorium fuel cycle design was found to require relatively high heavy metal loading (mainly with HEU). High HM loading means lower moderation ratio and harder neutron spectrum. Investigation of moderation insertion accidents (such as water ingress) has to be carried out to ensure desired reactivity response of the core for these fuel cycle designs.

Discharge burnup levels of thorium fuel cycles are higher due to longer fuel residence times required for efficient breeding of the $\mathrm{U} 233$ from fertile thorium. Such high burnup levels are more noticeable for the PBR-OTTO design. Increased burnup levels are less pronounced for the HEU Th-MOX cases where U233 breeding is more rapid. PBMR400-MEDUL discharge burnup levels in all cases are higher than PBR-OTTO levels, since fuel passes 6 times through the core. Here, the increase in burnup levels of thorium based fuel are modest $2 \%-5 \%$. The SWU utilization is reduced for the thorium fuels by $5 \%$ to $15 \%$, for the assumed tail enrichment setting of $0.25 \%$. The reduced SWU utilization is due to the higher uranium enrichment required for efficient thorium utilization.

The prospect that multi zone (simulating SBU concept) loading will enhance NUU performance by reducing core leakage has not been materialized. This is likely to be due to the long neutron mean free path of the nearly homogenous core with graphite moderation. A minor improvement of only $1 \%$ in the NUU results has been achieved for the 5 loading zone scheme. Therefore, it is not recommended to introduce multi-zone loading scheme for this configuration. It is however recommended to evaluate multi-zone loading scheme for the MEDUL fuel management. 
Commonly, MEDUL fuel management scheme is more efficient than the OTTO fuel management scheme; since the axial power distribution is more uniform and the power peaking is reduced. In the current work, the investigated MEDUL fuel management scheme was applied to PBMR design which has relatively high neutron leakage (tall and narrow core geometry) and hence results in less efficient NUU values than the large OTTO core. But because PBMR has higher leakage than HTR, the advantage of the MEDUL scheme is diminished.

PBMR400 with MEDUL fuel management scheme NUU results are lower than those of the PBR with the OTTO fuel management scheme, although the MEDUL fuel management scheme is more efficient than the OTTO scheme. This may be explained by the core geometry of the PBMR400, which features higher core leakage and thus less efficient NUU. The optimization algorithm developed in this study may help achieving the optimal fuel cycle objectives more easily than traditional parametric studies methods. For future work, it is suggested to implement the optimization procedure for multi objective functions which may better suit designers' and plant operators' goals.

\section{Acknowledgements}

The first author acknowledges the support of the Israel Electric Corporation for providing resources for performing this research towards the first author's Ph.D. degree at Ben-Gurion University in Israel. 


\section{References}

1. U.S. DOE Nuclear Energy Advisory Committee and the Generetion IV International Forum. "A Technology Roadmap for Generation IV Nuclear Energy Systems". 2002. GIF-002-00.

2. NGNP Industry Alliance Limited. NGNP. "Next Generation Nuclear Plant". [Online] 2010. Accessed: 12/2014. http://www.ngnpalliance.org.

3. Teuchert, E. "Once through Cycles in Pebble Bed HTR". KFA, Julich. 1977. Jul1470 .

4. Baumer, R and Kalinowski, I. "THTR Commissioning and Operating Experience". Eleventh International Conference on the HTGR. 1989. Dimitrovgrad, Russia.

5. Zhang Z., Wu Z., Wang D., Xu Y., Sun Y. and Li F. "Current Status and Technical Description of Chinese 2x250MWth HTR-PM Demonstration Plant". Nuclear Engineering and Design. 2009, Vol. 239, pp. 1212-1219.

6. Hawari, A I, et al., et al. "Assessment of on-line burnup monitoring of pebble bed reactor fuel using passive gamma-ray spectrometry". Nuclear Science, IEEE Transactions. 2002, Vol. 49, 3, pp. 1249 - 1253.

7. Mulder, E. and Teuchert, E. "Characteristics of a Different Fuel Cycle in PBMR400 for Burning Reactor Grade Plutonium". Proceeding HTR2006: 3rd International Topical Meeting On HTR Technology. 2006.

8. Shropshire, D. E. and Herring, J. S. "Fuel-Cycle and Nuclear Material Disposition Issues Associated with High-Temperature Gas Reactors". ANES, Miami Beach, Florida, USA. 2004.

9. Ferhat, A.; Su'ud, Z.; Asril, P.; Fenny, R. and Debby, M. "Design Study of Long Life HTGR Using Thorium Cycle". International Conference on Advances in Nuclear Science and Engineering in Conjunction with LKSTN. 2007.

10. Boer, B. and Ougouag, A. M. "Core Analysis, Design and Optimization of a Deep-Burn Pebble Bed Reactor". PHYSOR 2010 - Advances in Reactor Physics to Power the Nuclear Renaissance, Pittsburgh, PA, USA. 2010. 
11. Galperin, A., Reichert, P. and Radkowsky, A. "Thorium Fuel for Light Water reactors- Reduced Proliferation Potential of Nuclear Power Fuel Cycle". Science \& Global Security. 1997, 6, pp. 256-290.

12. Droizman, L. "Application of Thorium Fuel in GC-PBMR". Department of Nuclear Engineering, Ben-Gurion University, Israel. 2007. M.Sc. Thesis.

13. Teuchert, E. and Rütten, H. J. "Near Breeding Thorium Fuel Cycle in Pebble Bed HTR". IAEA-OECD Symposium on Gas Cooled Reactors. 1975.

14. Wols F., Kloosterman J. L., Lathouwers D. and Van Der Hagen T. "Core Design and Fuel Management Studies of a Thorium-Breeder Pebble Bed HighTemperature Reactor". Nuclear Technology. April 2014, Vol. 186, 1, pp. 1-16.

15. Boer, B.; Kloosterman, J. L.; Lathouwers D. and Van Der Hagen, T. "In-core Fuel Management Optimization of Pebble-bed Reactors". Annals of Nuclear Energy. 2009, Vol. 36, pp. 1049-1058.

16. Elbeltagi, E., Hegazy, T. and Colorni, A. "Comparison Among Five Evolutionary Optimization Algorithms". Advanced Engineering Informatics. 2005, pp. 19, 43-53,

17. Mckay, M. D., Beckman, R. J. and Conover, W. J. "A Comparison of three Methods for Selecting Values of Output Variables in the Analysis of Output From a Computer Code. Technometrics. 1979, 21, pp. 239-245.

18. Tran HN, Kato, Y., Muto Y. "Optimization of Burnable Poison Loading for HTGR Cores with OTTO Refueling". Nuclear Science and Engineering. March 2008, Vol. 158, 3, pp. 264-271. Technical Paper.

19. Ougouag, A M; Gougar, H D; Terry, W K; Mphahlele. "Optimal Moderation in the Pebble-Bed Reactor for Enhanced Passive Safety and Improved Fuel Utilization". Chicago, Illinois: PHYSOR2004, 2004.

20. OECD/NEA. "PBMR Coupled Neutronics/Thermal-hydraulics Transients Benchmark". s.1.: OECD/NEA In co-operation with PBMR Pty Ltd, Penn State University (PSU), 2013. JT03343064; NEA/NSC/DOC (2013) 10.

21. Tavron, B, Galperin, A and Shwageraus, E; Droizman, L. "PBMR400 Benchmark Calculations Phase I: Steady State Calculations". Proceedings of the 23th Conference of the Nuclear Societies in Israel. 2006, pp. 149-150. 
22. Reitsma, F. "The Pebble Bed Modular Reactor Layout and Neutronics Design of the Equilibrium Cycle". PHYSOR 2004, Chicago, USA. 2004.

23. Teuchert, E.; Hass, K. A.; Rutten, H. J., Brockmann, H.; Gerwin, H.; Ohlig, U. and Ohlig, U. "V.S.O.P (94) Computer Code System For Reactor Physics and Fuel Cycle Simulation". 1994. ISSN 0944-2952; JUL-2897.

24. University, Tsinghua. Institute of Nuclear and New Energy Technology. "HTR10". [Online] [Cited: 11 10, 2014.] Accessed:12/2014. http://www.tsinghua.edu.cn/publish/ineten/5696/index.html.

25. Teuchert, E.; Gerwin, H.; Hass, K. A. and Rütten, H. J. "Peu a peu': A New Fuelling Mode of the Pebble Bed Reactor". International Atomic Energy Agency. 1985. pp. 299-311. IAEA-TECDOC-358.

26. Kadak, A. C. and Bazant, M. Z. "Pebble Flow Experiments For Pebble Bed Reactors". 2nd International Topical Meeting on High Temperature Reactor Technology, Beijing, China. September 2004.

27. Bedenig, D., W. Rausch, and G. Schmidt. "Parameter Studies Concerning the Flow Behavior of a Pebble with Reference to the Fuel Element Movement in the Core of the THTR 300MWe Prototype Reactor". Nuclear Engineering and Design. 1968, Vol. 7, pp. 367-378.

28. Bedenig, D. "Ein Theoretisches Model Zur Beschreibung Des KugelhaufenFliessverhaltens Im Core Eines Kugelhaufen-Reaktors". Nuclear Engineering and Design. 1967, Vol. 6, 5, pp. 479-488. In German.

29. Tavron, B, Shwageraus, E and Galperin, A. "Optimization of OTTO fuel management in Pebble-Bed reactors using Particle Swarm Algorithm". Proceedings of the 25th Conference of the Nuclear Societies in Israel. 2012.

30. World Information Service on Energy - Uranium Project. WISE-Internet Site. "Nuclear Fuel Cost Calculator". [Online] Accessed: 12/2014. http://www.wiseuranium.org/nfcc.html.

31. The Ux Consulting Company. "UxC Nuclear Fuel Price". [Online] [Cited: 12 10, 2014.] Accessed: 12/2014. http://www.uxc.com/review/UxCPrices.aspx.

32. Canon, B. "Thorium as a Secure Nuclear Fuel Alternative". Journal of Energy Security. [Online] April 2009. Accessed: 12/2014. http://ensec.org/index.php. 
33. McKay, D. "An Introduction to Nuclear Fuel for David McKay". The Energy from Thoriun Foundation. [Online] [Cited: 12 10, 2014.] Accessed: 12/2014. http://energyfromthorium.com/2008/11/19/an-introduction-to-nuclear-fuel-for-davidmckay-2/.

34. Grubert, E.; Parks, B.; Schneider, E. and Sekar, S. "Pebble Bed Modular Reactor Versus Other Generation Technologies: Costs ans Challenges for South Africa". GLOBAL 2011, Makuhari, JAPAN. 2011. 